\title{
Jogos de linguagem de conotação obscena em Romeu e Julieta: estudo comparativo de três traduções
}

\author{
Ana Karina Braun ${ }^{1}$ \\ Patrícia C. Ramos Reuillard ${ }^{2}$
}

\begin{abstract}
This article proposes a comparative study of different translations of Romeo and Juliet by William Shakespeare concerning the polysemy, defined as a condensation of more than one signified in the same signifier and potential source of equivalence in translation. It is represented in this work by double meaning expressions with obscene connotation named jogos de linguagem (language games). The analysis is based on theoretical assumptions of translation that define it as an interpretative and communicative process based on the studies of Rosa Rabadán (1991) and Hurtado Albir (2001). It aims at studying the translation of polysemy in this literary work through the comparison and analysis of three translations into Portuguese. They are Beatriz Viégas-Faria's translation, published in 1998, Bárbara Heliodora's translation, published in 2004, and Elvio Funck's translation, published in 2011. Through this analysis and comparison, we hope to evince that the translation of the jogos de linguagem, which are a continuous characteristic of William Shakespeare's work, requires a careful treatment concerning the reproduction of the communicative function of comicality through the exploration of sexuality. Therefore the analysis of the treatment of polysemy in the translations will also allow us to know its effects in the production of texts of the target language and to reflect on the best way of reproducing them in order to propose strategies to solve this kind of translation problem considering the necessity of an adjustment towards the social and cultural context in which they are inserted.
\end{abstract}

Keywords: literary translation; polysemy; language games; non-equivalence; sexuality.

Resumo: Este artigo apresenta um estudo comparativo de traduções da obra Romeu e Julieta, de William Shakespeare, no que se refere à polissemia, entendida como uma condensação de significados em um só significante e fonte potencial de inequivalência na tradução. Nessa obra, a polissemia é representada pelas expressões de duplo sentido com conotação obscena, aqui denominadas jogos de linguagem. A análise se sustenta nos pressupostos teóricos da tradução de Rosa Rabadán (1991) e Hurtado Albir (2001), que a compreendem como um processo interpretativo e comunicativo. O objetivo é estudar a tradução da polissemia nessa obra, a partir da comparação e da análise de soluções em três traduções para o português: Beatriz Viégas-Faria (1998), Bárbara Heliodora (2004) e Elvio Funck (2011). As respectivas análises e comparações evidenciam que a tradução dos jogos de linguagem, característica constante na obra de William Sha-

1 Universidade Federal do Rio Grande do Sul

2 Docente dos Cursos de Graduação e Pós-Graduação em Letras da UFRGS. 
kespeare, requer um tratamento cuidadoso no que diz respeito à reprodução de sua função comunicativa de comicidade através da exploração do tema da sexualidade. Portanto, a análise do tratamento dado à polissemia nas traduções permitirá, também, conhecer seus efeitos na produção de textos da língua alvo e refletir sobre a melhor maneira de reproduzi-los através de estratégias que solucionem os problemas de tradução, considerando a necessidade de uma adaptação ao contexto social ou à cultura em que serão inseridos.

Palavras-chave: tradução literária; polissemia; jogos de linguagem; inequivalência; sexualidade.

\section{Introdução}

O escritor William Shakespeare é atualmente considerado um gênio não apenas da literatura inglesa, mas também da literatura universal. Tendo escrito mais de trinta peças teatrais, além de poemas, entre a segunda metade do século XVI e a primeira do século XVII, sua genialidade se justifica pela capacidade de dar dramaticidade, dinamicidade e força às suas peças; pela habilidade em jogar com as palavras e por seu caráter universal, que se percebe em sua sensibilidade para abordar temas e criar personagens atemporais e que representam as qualidades e as falhas inerentes ao ser humano, com as quais o público se identifica.

Do ponto de vista dos estudos da tradução, sua obra apresenta grande interesse, haja vista o caráter polissêmico da linguagem shakespeariana e os problemas que essa característica engendra para o tradutor.

Este artigo busca apresentar um estudo sobre o tratamento dado à polissemia em traduções do inglês para o português na obra Romeu e Julieta ${ }^{3}$, comparando e analisando algumas traduções dos jogos de linguagem de conotação obscena empregados pelo personagem Mercúcio na obra Romeu e Julieta.

As traduções escolhidas para a análise - Beatriz Viégas-Faria (1998), Barbara Heliodora (2002) e Elvio Funck (2011) - destinam-se a públicos variados e têm funcionalidades e estratégias de tradução distintas, mas estão igualmente atentas à questão dos jogos de linguagem. As traduções de Viégas-Faria e Heliodora estão voltadas a um público geral e empregam uma linguagem contemporânea. BeatrizViégas-Faria traduz em prosa o texto original, escrito predominantente em verso. $\mathrm{O}$ texto de Heliodora, que também traduz para o teatro, está em prosa e verso, oscilando entre uma linguagem que ora se aproxima do popular, ora do erudito. Já a tradução de Funck, em prosa e verso, visa um público mais específico, constituído por profissionais e estudantes das áreas de literatura e tradução, e tem um cunho mais didático, o que se confirma pela grande quantidade de notas de rodapé explicativas, especialmente no que diz respeito ao uso de expressões inglesas de uso arcaico ou a informações históricas que contribuem para uma melhor interpretação do texto.

Com o intuito de contextualizar a produção shakespeariana, faremos, de início, uma retomada dos principais fatos históricos e políticos e da cena cultural da Inglaterra elisabetana, seguida de uma análise do tratamento dado então à sexualidade, o qual teve

3 BRAUN, Ana Karina Borges. O tratamento da polissemia em traduções da obra Romeu e Julieta de William Shakespeare. Porto Alegre: UFRGS, 2016. 120 f. Tese (Mestrado em Teorias Linguístias do Léxico) - Programa de Pós-Graduação Letras, Instituto de Letras, Universidade Federal do Rio Grande do Sul, Porto Alegre, 2016. 
influência direta na produção literária da época. De fato, a linguagem obscena revelada através das metáforas e dos jogos de linguagem obscenos, tão apreciados pela plateia elisabetana, foi largamente explorada pelos dramaturgos, dentre os quais se destacou William Shakespeare.

Em segundo lugar, nossa reflexão acerca do processo tradutório se embasará nos conceitos de Hurtado Albir e Rosa Rabadán e na observação de fatores externos ao texto original (políticos, históricos, filosóficos, culturais, etc.) que influenciam tanto sua produção bem como sua reprodução ou tradução, em um contexto específico.

Por fim, apresentaremos uma breve amostra dos jogos de linguagem e de suas traduções.

\section{Contextualização}

O período em que viveu o dramaturgo é conhecido como era elisabetana e se caracterizou por um grande desenvolvimento econômico, científico e cultural, embora tenha também conhecido momentos de crise social, ocasionada pela rivalidade entre faç̧ões políticas. Tal período possibilitou o florescimento do teatro.

Quando, por volta de 1558, a rainha Elisabete I permitiu a volta das apresentações teatrais públicas na Inglaterra, proibidas no breve reinado de Eduardo VI, teve início a era do teatro elisabetano. Esse período se estendeu até 1642, data do fechamento dos teatros pela facção puritana do parlamento durante a Revolução Inglesa, e corresponde às peças de teatro produzidas sob forte influência dos clássicos gregos e latinos, em decorrência do Humanismo.

Os autores do teatro elisabetano abordavam em suas peças temas diversos, que abrangiam não só personagens e fatos históricos da antiguidade clássica, como também fatos da história da Inglaterra e de seus monarcas. Pretendiam popularizar as peças através de temas atraentes para um público constituído de todas as classes sociais, em uma época em que a sociedade inglesa começava a se libertar da rígida hierarquia social dominante na Idade Média, oportunizando à população algum conhecimento da antiguidade clássica através do teatro.

O drama elisabetano, focado nas relações interpessoais e sociais, explorava, através dos efeitos cênicos, o tragicômico, as emoções violentas, as paixões e o realismo dos personagens, com os quais a plateia se identificava. Através da renovação da métrica, com o uso do verso branco, das entrelinhas, dos jogos de linguagem, buscava-se transmitir uma mensagem ao público. São exemplos disso Macbeth, atormentado pela culpa; Romeu e Julieta, jovens amantes cujo suicídio pune famílias inimigas que sobrepõem a disputa pelo poder ao amor; Rei Lear, levado à loucura pela traição das filhas; Hamlet, consumido pela suspeita do assassinato de seu pai, o rei Hamlet, pelo próprio irmão Cláudio.

Apesar da popularidade, os teatros não eram bem vistos pelas autoridades de Londres e estavam proibidos na cidade. O crescente movimento puritano na Inglaterra, que se opunha ao absolutismo do rei Carlos I e que culminou em 1642 com o início da Guerra Civil, hostilizava o teatro assim como outras formas de manifestação cultural, consideradas imorais e desafiadoras à ordem pública. Tanto os personagens femininos como os masculinos eram interpretados por homens. A ausência de atrizes se justifica pela herança do teatro medieval, cujas peças de caráter religioso e didático, as moralidades, eram apenas representadas por atores amadores e nunca por atrizes. Essa tradição se perpetuou no teatro elisabetano, mas os atores deixaram de ser amadores. A participação das mulheres se limitava a outras funções no teatro, tais como a preparação do figurino. 
Nos primórdios do teatro elisabetano, na segunda metade do século XVI, os cenários eram muito simples e normalmente ao ar livre, o que requeria uma imaginação fértil da plateia, que era levada a imaginar seu próprio cenário através das falas dos personagens. Eram construções simples de madeira ou pedra, descobertas, com formato circular ou hexagonal e com amplo espaço interno. Os balcões e as galerias estavam dispostos ao redor do teatro e a decoração era singela. A cenografia também era escassa e não havia interrupções entre um ato e outro, diminuindo o tempo de representação das peças. Tampouco havia cortinas no palco, o que criava a necessidade de expressões que indicassem a entrada ou saída de atores em cena, tais como Farewell (adeus), I'll go along (partirei), etc., ou mesmo de versos rimados. Somente mais tarde, por volta de 1709, a divisão das peças em atos e cenas foi introduzida pelo dramaturgo, poeta e editor da primeira edição moderna da obra de Shakespeare, Nicholas Rowe. Os atores interpretavam em meio ao público, com o qual interagiam. Teatros com estrutura mais próxima à dos modernos, como o The Globe, começaram a ser construídos apenas no início do século XVII.

Em virtude da diversidade social da plateia, os teatros elisabetanos se organizam em distintos níveis. Dessa forma, às camadas mais pobres, que ficavam em pé na parte principal do auditório - groundlings -, destinavam-se os ingressos mais baratos. Ao redor dos groundlings estavam as balconies, semelhantes às arquibancadas cobertas de um estádio de futebol com assentos, cujos ingressos mais caros se destinavam às camadas sociais mais abastadas.

Quanto aos parâmetros que norteavam o teatro elisabetano no que se refere aos temas, recursos linguísticos, estrutura cênica, etc., a tradutora e crítica literária Heliodora (2001, p. 35) afirma que "Os criadores do teatro elisabetano não tinham princípios estéticos normativos a seguir; seu critério básico ao escrever para o teatro parece ter sido "se funcionar bem no palco pode, se não funcionar não pode".

Quando Elisabete I faleceu em 1603, Jaime I lhe sucedeu e seu reinado deu continuidade à época de ouro do teatro elisabetano. Algumas peças de William Shakespeare escritas durante o reinado de Jaime I são Otelo, Macbeth, Rei Lear, Antônio e Cleópatra, Conto de Inverno e A tempestade. Assim como as obras literárias daquele período, tais como Hamlet, que continha várias alusões à corte inglesa da rainha Elisabete, as desse novo período seguiram contendo referências diretas ao monarca. Segundo Funck (2012, p. 205), Macbeth teria sido escrita "sob medida para o rei Jaime I": única a se passar na Escócia, seu enredo relata o assassinato do rei Duncan pelas mãos de Macbeth, seu parente e general que lhe sucede no trono.

Foi nessa época que viveu o dramaturgo e poeta inglês William Shakespeare. Nasceu em 1564, em Stratford-upon-Avon, e faleceu em 23 de abril de 1616 na mesma cidade. Shakespeare teria concluído o ensino médio, onde estudou latim, retórica, lógica e os textos clássicos latinos e gregos. Nas aulas de retórica, os alunos desenvolviam e exercitavam a habilidade da escrita e da fala através da produção de cartas, ensaios ou discursos que eram apresentados oralmente. Fazia parte desse exercício o emprego de figuras de linguagem tais como metáfora, alegorias e hipérbole. Sem dúvida, toda essa formação clássica contribuiu para sua formação como escritor, além do talento excepcional para o uso da linguagem.

Entre 1585 e 1588, Shakespeare mudou-se para Londres, quando a cidade se encontrava em plena efervescência cultural, o que propiciou o início de sua carreira em companhias de teatro, tais como a Queen's Men e a Lord Strange's Men. Teria trabalhado em diversas funções antes de se tornar ator, escritor e, mais tarde, um dos proprietários do teatro The Globe (construído em 1599) e do Blackfriars (construído em 1609). A efervescência cultural resultante dos ideais humanistas proporcionou o ambiente perfeito para a 
evolução de seu talento linguístico, e a redescoberta dos clássicos greco-latinos contribuiu para a composição de sua obra. O dramaturgo escreveu peças de gêneros variados, muitas vezes recriando clássicos da literatura latina e grega ou utilizando-se de sua mitologia, sempre buscando temas que, de alguma forma, estivessem relacionados a fatos da realidade vivenciada por sua plateia. No entanto, suas peças foram classificadas em gêneros distintos - tragédia, comédia, peças históricas e poemas - apenas após sua morte, quando sua obra completa foi publicada pela primeira vez em um único volume, sob o nome de First Folio, por John Hemings e Henry Condell.

Entre as históricas, pode-se citar Ricardo III e Henrique VI. Entre as comédias, encontram-se Sonho de uma noite de verão e A tempestade. As tragédias de Shakespeare, por sua vez, são atribuídas a uma fase mais tardia de sua vida, que compreende o período entre 1601 e 1608 . O escritor se baseou no preceito de tragédia de Aristóteles para elaborar suas peças, segundo o qual o caráter admirável, porém não incorruptível do herói, torna-o humano e, por essa razão, mais próximo da plateia que, em uma espécie de catarse, se compadece do mesmo e expurga ou purifica seus sentimentos. Entre as mais conhecidas estão Romeu e Julieta, Hamlet, Otelo e Macbeth.

A obra que analisamos, Romeu e Julieta, foi escrita entre 1592 e 1595 e é uma das mais conhecidas do autor. Do ponto de vista linguístico, é classificada por Heliodora como uma tragédia lírica, pois pertence a um período em que Shakespeare utilizou intensa linguagem poética nos distintos gêneros em que escreveu e, em especial, nessa tragédia. Day (1963, p. 197, tradução nossa), por sua vez, classifica-a como "comédia romântica".

Essa peça é baseada no poema intitulado The Tragicall Historye of Romeus and Juliet (1567), de Arthur Brooke, que se baseou na obra Romeo e Giullieta do escritor italiano Matteo Bandello (1554), uma adaptação do mito grego de Píramo e Tisbe. A peça tem como tema o amor proibido de dois jovens, ocasionado pela rivalidade entre suas famílias. De um lado, os Capuleto, família de Julieta, e, de outro, os Montéquio, família de Romeu. Em uma tentativa de ficarem juntos, os jovens decidem fugir, mas, por forças do destino ou por um mal-entendido, acabam suicidando-se. As ações de Romeu e Julieta concentram-se em um curto espaço de tempo de cinco dias, ao contrário do original, que se desenrola em um período aproximado de nove meses. Nessa obra se percebe a genial capacidade de Shakespeare de dar dramaticidade, velocidade e força às suas versões.

Embora o amor seja, aparentemente, o tema central de Romeu e Julieta, tema recorrente em sua obra, Heliodora chama a atenção para a rivalidade entre os Capuleto e os Montéquio e para o fato de que o tema do jogo de poder se sobreponha ao do amor. Acrescenta que o conflito entre as duas famílias é uma representação da guerra civil, da disputa de poder e dos danos que ela causa à população. O desfecho trágico de Romeu e Julieta é consequência do ódio e da intolerância entre suas famílias bem como uma forma de punição por seus atos que perturbaram a harmonia da comunidade. Isso representava, para Shakespeare, "a imagem do mais negativo e terrível que pode acontecer ao estado" (HELIODORA, 2001, p. 77-78).

\section{A linguagem de Shakespeare e a polissemia}

A linguagem era de primordial importância no teatro elisabetano, que não dispunha dos recursos do teatro moderno (cenário, iluminação, etc.) e que se servia da palavra e 
de todos os recursos da retórica: o set speech, o emprego de pensamentos, conceitos e epigramas e de sonetos, o patterned speech e os image clusters ${ }^{4}$.

Para alcançar uma maior interação com a plateia, Shakespeare empregava variados recursos linguísticos, nos quais se vê sua incontestável habilidade e gosto pelos jogos de linguagem, criação de palavras, metáforas e trocadilhos, como veremos a seguir.

$\mathrm{O}$ dramaturgo soube utilizar a riqueza cultural e linguística que caracterizava a língua inglesa em suas peças, em um momento em que ela passava a ter o status de língua literária pela primeira vez, desde a conquista normanda em 1066. Essa riqueza que lhe possibilitou "jogar" com a língua se deveu ao processo de transformação por que ela estava passando em pleno Renascimento, uma vez que estava livre de instrumentos normativos rígidos reservados apenas ao latim, que era, de fato, a língua estudada nas escolas. Além disso, desde o Middle English, o inglês da Idade Média, a língua havia perdido as terminações morfológicas (prefixos, sufixos e desinências), o que também lhe dava maleabilidade; muitas vezes, a diferença entre um substantivo e um verbo passava a ser percebida através do contexto devido à ausência de marcas formais que os diferenciassem, como ocorre ainda nos dias de hoje.

Portanto, a língua inglesa estava suscetível a mudanças e empréstimos, com os quais Shakespeare soube lidar de forma brilhante, embasado em seu sólido conhecimento da língua, em uma época em que a cultura era muito mais auditiva do que visual e que o público ouvia as peças em um teatro desprovido de grandes cenários, maravilhando-se com o poder das palavras.

O segundo aspecto desse "jogo" que Shakespeare fazia com as palavras diz respeito ao uso de metáforas que ele, cuidadosamente, relacionava aos temas mais familiares de seu público, tais como jardinagem, jogos, pesca, etc., criando uma espécie de pano de fundo para suas peças. Um exemplo se encontra em Hamlet, peça em que o dramaturgo lança mão de um conjunto de metáforas inter-relacionadas que fazem referência ao "adoecimento, podridão, decadência e morte", em concordância com o tema da peça, que narra a trama da traição e morte do rei Hamlet da Dinamarca por seu próprio irmão Cláudio.

O terceiro e último é o uso dos trocadilhos. Assim como todos os outros aspectos de sua linguagem, os trocadilhos - cujo princípio se baseia na polissemia - serviam ao propósito de entreter o público provocando o riso e maravilhá-lo com a riqueza e a criatividade de suas construções. Justificando a definição da polissemia, que, segundo Rabadán (1991, p. 120) é "uma condensação de significados em um único significante", os trocadilhos shakespearianos, aqui denominados jogos de linguagem, tinham uma conotação obscena.

Vejamos um exemplo na fala das personagens Sansão e Gregório, servidores dos Capuleto, que, na cena 1 do ato I, provocam uma discussão com os servidores dos Montéquio ao se referirem à superioridade de seus patrões. Ao empregar o verbo to stand, que significa ficar de pé, mas que também conota "ter uma ereção", Sansão joga com esse duplo sentido:

Sampson: A dog of the house of Montague moves me to stand. (EVANS apud FUNCK, 2011, p. 23)

Sansão: Da casa dos Montéquio, até um cachorro me incomoda. (VIÉGAS-FARIA, p. 9, 1998)

O jogo de linguagem do original tem continuidade com a resposta de Gregório e é reproduzido na tradução através da expressão "enfrentar o inimigo, firme, teso, de pé", resgatando o jogo de palavras do texto original:

4 Para mais detalhes, ver HELIODORA, Bárbara. Falando de Shakespeare. São Paulo: Perspectiva, 2001. 

moved, thou runn'st away. (EVANS apud FUNCK, 2011)

Gregório: Ficar incomodado implica mexer-se; e ser valente é enfrentar o inimigo, firme, teso, de pé; portanto, se ficas incomodado, não ficas parado e foges. (VIÉGAS-FARIA, p. 9, 1998)

Segundo Kiernan (2008, p. 1), entreter o público não era a única razão pela qual Shakespeare teria recorrido com tanta frequência à linguagem de conotação obscena. A autora esclarece que, através desses jogos de linguagem, que faziam parte do subtexto que enfatizava o impacto dramático de suas cenas, Shakespeare tratava de tópicos relacionados à moralidade, à política e à filosofia. Além disso, ela enfatiza a importância de se reconhecer a linguagem obscena da obra de Shakespeare como uma forma de análise das distintas facetas da essência humana através da sexualidade e acredita que nesse ponto, especificamente, resida o brilhantismo do dramaturgo. Portanto, ignorar esse aspecto de sua linguagem e vê-lo como um gênio puro e imaculado "é um grande desserviço" (KIERNAN, 2008, p. 27-45) .

Esse "desserviço", essa tentativa de suavizar a linguagem obscena de Shakespeare, prática comum entre os editores e tradutores de sua obra entre os séculos XVI e XX, tem duas importantes consequências.

A primeira diz respeito à consequente descaracterização da obra de Shakespeare por meio de uma "higienização", pois "com o passar dos anos, os trocadilhos sexuais de Shakespeare mais indecentes se tornaram invisíveis em edições e apresentações de suas peças, o que significa que o mundo foi privado de um aspecto significante e paradoxalmente sério de sua obra" (Ibid, p. 30 e 31-45) ${ }^{6}$. Ou seja, essa "higienização" implica a perda de um entendimento maior do significado de sua obra no que concerne a toda uma gama de valores, preceitos, interpretações de fatos políticos, históricos, etc., revelados através dos jogos de linguagem obscenos.

A segunda consequência concerne aos valores morais e religiosos de uma sociedade que se revelam por meio dessa "higienização", pois através do tratamento dado à sexualidade, manifestada na literatura - nesse caso específico, através dos jogos de linguagem obscenos -, percebem-se as manobras, as formas de controle sobre o indivíduo que está atrelado às regras de comportamento que restringem ou mesmo impossibilitam uma discussão aberta acerca da sexualidade.

Da mesma forma, no que se refere à linguagem obscena daquele período, especialmente à linguagem de Shakespeare, Partridge $(1968, \text { p. } 5)^{7}$ observa que o autor tinha interesse, curiosidade pelo sexo e sua misteriosa influência sobre a vida e o caráter humanos. Além disso, este autor descreve a linguagem obscena de Shakespeare como uma linguagem

5 No original: "But this is to him a great disservice". Esta tradução e todas que seguem de Kiernan (2008) são de nossa autoria.

6 No original: "But in the years since his day, Shakespeare's most indecent sexual puns have been all but invisible in editions and performances of his plays, which has meant that the world has been deprived of a significant, and paradoxically serious, aspect of his work".

7 No original: "Shakespeare was, physically, a pagan; also, he took a lively, very curious interest in sex. He was no mere 'instinctive' sensualist, but an intellectual voluptuary and a thinker keenly, shrewdly, penetratingly, sympathetically probing into sex, its mysteries, its mechanism, its exercise and expertise, and into its influence on life and character". Esta tradução e todas que seguem de Partridge (1968) são de nossa autoria. 
de "vulgarismos apenas no senso filológico" (PARTRIDGE, 1968, p. 9)8, acrescentando que o dramaturgo "apenas se utilizava de gracejos anatômicos (anatomical witticism) ou da piada funcional (functional joke) que remetessem à sexualidade com espirituosidade" (Ibid, p. 9) ${ }^{9}$. Tal observação remete à ideia de que os jogos de linguagem sexuais de Shakespeare estejam intrinsecamente inseridos no contexto da peça, da situação descrita, do diálogo. Muitas expressões cujo sentido denotativo é inocente conotam um sentido novo e obsceno em determinados diálogos e situações.

$\mathrm{E}$, finalmente, o fato de esse tema ter sido constantemente explorado na obra shakespeariana e naquela de autores contemporâneos a ele comprova a relação entre a sexualidade e as formas de controle da sociedade e remete, portanto, à análise e discussão acerca da sexualidade na era elisabetana. Acerca disso, Kiernan (2008, p. 5) $)^{10}$ observa uma capacidade aguçada da plateia elisabetana em identificar o subtexto das peças teatrais. A autora levanta duas razões que justificariam essa capacidade de interpretação: a familiaridade da plateia com a decifração de códigos e com a linguagem obscena, e a significação dessa prática, através da qual o público era instigado e desafiado em termos de comportamento.

Dessa forma, pode-se dizer que o público encontrava no teatro uma possibilidade de extravasar ou liberar desejos, emoções e ideias reprimidas. E o riso decorrente dos trocadilhos obscenos de Shakespeare, por exemplo, enfatizados pelos gestos e pelo tom de voz dos atores, parece ser um bom exemplo disso. Macrone (1998, p. 25) observa que essa catarse do público elisabetano, não apenas no que concerne à obscenidade, mas também à violência e às misérias das ruas, lotava os teatros: "O público de então, assim como o público de hoje, queria, de fato, ser chocado, assustado ou mesmo nauseado. E tais emoções, degradantes ou prurientes segundo o ponto de vista, eram definidas por Aristóteles, de forma nobre, como a catarse" $" 11$.

\section{Tradução}

Neste trabalho, adotamos as ideias de Hurtado Albir (2001) sobre o fenômeno tradutório, a qual entende a tradução como um ato de comunicação entre sistemas linguísticos distintos, mediado pelo tradutor. Essa visão sustenta nosso próprio entendimento do processo tradutório dos jogos de linguagem do texto original em inglês de Romeu e Julieta para o português, que consiste na mediação da língua e cultura de partida entre a língua e cultura de chegada, a fim de manter a função comunicativa desses jogos do texto-fonte, que se expressa pela comicidade das expressões de duplo sentido de conotação obscena. Além disso, ao concordar que o público-alvo também é um fator determinante no processo da tradução, como se verá a seguir, encontramos outro ponto em comum com os conceitos de Hurtado Albir. A distância não apenas linguística mas também cultural desse texto de aproximadamente quatrocentos anos requer uma observação e mediação ou adaptação minuciosas do

8 No original: "[...] vulgarisms only in the philological sense".

9 No original: "Shakespeare was not a Rabelais: he took very little pleasure in the anatomical witticism and the functional joke, unless they were either witty or sexual".

10 No original: "People spoke a language that was full of figures of speech - bawdy, colourful, or just plain gross - to describe or disguise the cruel facts of life: poverty, the plague, veneral disease, a high infant mortality rate, slow painful death, the brutal violence in many forms that was everywhere around them. Life in Shakespeare's England was - for many of its population - brutal, hard and raw".

11 No original: "Many playgoers then, like many moviegoers today, actually wanted to be shocked, frightened, or even disgusted. You might call such emotions degrading or prurient; but Aristotle had a more ennobling word for them: catharsis". 
texto para seu público-alvo, inserido em um contexto social, histórico, linguístico e cultural totalmente diverso daquele em que se encontrava a plateia shakespeariana.

Outras questões relevantes abordadas pela autora dizem respeito à finalidade e às características ou traços definitórios da tradução e à visão da tradução como um ato de comunicação, operação textual e atividade cognitiva.

A reflexão acerca da finalidade e características da tradução está baseada em quatro pressupostos básicos: a razão ou necessidade de se traduzir, motivada pelas diferenças linguísticas e culturais; a finalidade comunicativa, uma vez que a função de um texto é comunicar; o destinatário da tradução que necessita dela por desconhecer a língua e/ou cultura do texto fonte; e a finalidade da tradução que a condiciona. A título de ilustração, um texto clássico da literatura, como a obra que analisamos, pode ser traduzido para uma edição de livros de bolso (por exemplo, a tradução de Viégas-Faria ou a de Heliodora) ou uma edição erudita bilíngue (como a de Elvio Funck). A autora acrescenta que o ato da tradução requer do tradutor habilidades linguísticas e extralinguísticas. Essas últimas compreendem não apenas o conhecimento do tema do texto fonte, mas também da cultura de chegada, habilidade de transferência ou de compreensão e produção de textos, e conhecimento instrumental, que se refere ao mercado laboral, conhecimentos de informática, etc.

Hurtado Albir descreve os traços definitórios da tradução através de seis princípios básicos, que retomaremos brevemente: princípio da primazia da comunicação e adequação à língua de chegada; princípio da atualização textual ou sentido; princípio da intervenção do contexto; princípio dos aspectos culturais e destinatário da tradução; princípio da vinculação textual e da finalidade de tradução; e princípio da tradução como processo mental.

O primeiro princípio, o da primazia da comunicação e adequação à língua de chegada, diz respeito à utilização de meios linguísticos distintos para a mesma intenção comunicativa em línguas também distintas. Dessa forma, as formas de cumprimento ou os provérbios, por exemplo, são próprios de cada língua. Um exemplo se encontra na expressão Good den empregada por Mercúcio em Romeu e Julieta (ato II, cena 4) quando se dirige à Ama de maneira jocosa ao se servir do duplo sentido obsceno da expressão den, que significava na época tanto "boa tarde" quanto, "antro" ou "vagina". O cumprimento desse princípio requer do tradutor, portanto, a observância e reprodução da função comunicativa dessa expressão no texto original que é a de gerar comicidade através da exploração do duplo sentido.

O segundo princípio é o da atualização textual ou do sentido. A autora chama a atenção para a consideração do sentido das palavras e frases em um determinado contexto e gênero textual, sob pena de se cair em casos de intraduzibilidade ou inequivalência, quando não se encontra uma expressão de sentido equivalente na língua de chegada. Essa atualização pode ser ilustrada por uma fala do personagem Mercúcio (ato II, cena 4): quando se dirige de forma maliciosa à Ama de Julieta, ele faz uso do duplo sentido das expressões hand e prick em "the bawdy hand of the dial is now upon the prick of noon hand". $\mathrm{O}$ duplo sentido se expressa através da expressão hand, que pode ser atualizada tanto como "mão" quanto como "ponteiro do relógio", e prick, que significa "ponto" ou "marca", mas que também conota "pênis". Funck (2011, p. 114-115) ofereceu a seguinte solução para esse trecho: "o ponteiro safado está agora bem em cima do ponto do meio-dia".

O princípio da intervenção do contexto refere-se ao significado de uma palavra inserida em um contexto. Em outra fala (ato I, cena 4), ao tentar animar Romeu, que diz ter um mau presságio em decorrência de um sonho e se mostra preocupado e pouco disposto a participar do baile de máscaras dos Capuleto, Mercúcio emprega um espirituoso discurso no qual faz referência à Rainha Mab. Segundo o folclore da época, ela "é a agente que 
as fadas usam para que as pessoas 'dêem à luz' sonhos estranhos” (KITTREDGE apud FUNCK, 2011, p. 63). A completude da função comunicativa dessa metáfora que alude aos sonhos requer do espectador ou leitor um conhecimento prévio a respeito dessa referência folclórica.

O quarto princípio tange aos aspectos culturais e ao destinatário da tradução e pode ser ilustrado pelo jogo de linguagem to raise a spirit in his mistress' circle (erguer um espírito dentro do círculo de sua amada), uma vez que precisa ser adaptado tanto à cultura de chegada como ao destinatário da tradução. Ao empregar essa expressão (ato II, cena 1, EVANS apud FUNCK, 2011, p. 83), Mercúcio faz referência à consumação do ato sexual entre Romeu e sua amada. Na era elisabetana, a expressão to raise a spirit significava literalmente erguer ou fazer aparecer um espírito (FUNCK, 2011, p. 83). No entanto, spirit também conotava pênis, assim como circle, vagina. Daí o jogo de linguagem que alude ao ato sexual, em que to raise a spirit conota uma ereção, complementado por in his mistress' circle, que conota a penetração. No entanto, essa conotação sexual, base da função comunicativa do texto e evidente para o público elisabetano, já não o é para o público contemporâneo. Portanto, o tradutor precisa se servir de recursos que forneçam essa informação, seja através de notas de rodapé, seja através de expressões adaptadas à língua e à cultura de chegada e que resgatem tal conotação.

O quinto princípio é o da vinculação textual e a finalidade da tradução, que diz respeito à adaptação da tradução do texto fonte em função do gênero textual e sua finalidade. A autora esclarece que cada gênero textual específico com finalidades distintas requer estratégias de tradução diferenciadas.

O sexto e último princípio vê a tradução como resultado de um processo mental ao qual o tradutor é submetido na busca de soluções tradutórias. Esse processo requer uma compreensão do texto original e conhecimentos linguísticos e extralinguísticos que lhe permitam fazer, em um segundo momento, uma transposição da língua fonte à língua alvo, tendo em mente a função do texto e o destinatário.

Hurtado Albir finaliza sua reflexão retomando o conceito da tradução a partir de três traços ou características (2001, p. 38-42): é um ato de comunicação devido à sua finalidade comunicativa, é uma operação textual, por estar situada no plano da fala, e é um processo mental, pois requer do tradutor uma compreensão do texto da língua fonte para, em seguida, reformulá-lo com os meios da língua do texto alvo.

A partir desses princípios, Hurtado Albir redefine a tradução como "um processo interpretativo e comunicativo que consiste na reformulação de um texto com os meios de outra língua que se desenvolve em um contexto social e com uma finalidade determinada" $(2001, \text { p. } 41)^{12}$.

\section{Equivalência e inequivalência}

O processo de reformulação de um texto fonte, que se dá através da utilização dos recursos de uma língua-alvo, e de sua inserção em um novo contexto social e/ou cultural requer, primeiramente, uma análise do sentido atualizado no texto original, seguida do levantamento das possibilidades de equivalência e/ou das possíveis inequivalências.

Falar de equivalência corresponde a buscar uma solução tradutória através da utilização de expressões ou palavras da língua do texto alvo que deem conta do sentido e da

12 Esta tradução e todas que seguem de Hurtado Albir (2001) são de nossa autoria. 
finalidade do texto fonte. Entretanto, há casos em que uma solução tradutória se revela inatingível e nos deparamos com o processo inverso, denominado inequivalência. Isso pode ser exemplificado pela expressão grave man proferida por Mercúcio pouco antes de morrer após um duelo com Teobaldo, primo de Julieta (ato III, cena 1). O jogo de linguagem resulta do duplo sentido de grave, que significa "sério, grave, sisudo" e "túmulo": "sério" porque um morto não ri; "túmulo" porque Mercúcio estará enterrado no dia seguinte (FUNCK, 2011, p. 139).

Para Rabadán (1991, p. 118) 13, "Quanto maior for a relevância da função intratextual, maior será o grau de dificuldade na transferência e, portanto, a atualização da equivalência potencial se verá reduzida aos próprios umbrais da tradução. Na maioria dos casos, a tradução semântica se apresenta como uma solução possível. No entanto, quando os significantes se convertem em significado, em conteúdo, tornando sua materialidade formal intransferível, ocorre uma impossibilidade de expressão da equivalência no texto alvo"14. Impossibilidade que a autora denomina inequivalência linguística. O que se busca nesses casos, portanto, é uma tradução da função comunicativa. Aqui, especificamente, inserem-se os jogos de linguagem de Romeu e Julieta, empregados de forma motivada no texto, uma vez que seu duplo sentido e sua conotação obscena buscam a comicidade. Essa função comunicativa é o que, de fato, deve ser reproduzido na língua alvo. Em muitos casos, essa reprodução representa um desafio ao tradutor, que necessita buscar, na língua-alvo, recursos diversos daqueles da língua-fonte a fim de manter a mesma função comunicativa do texto fonte.

\subsection{Polissemia e jogos de linguagem}

O conceito de polissemia é relacionado, por Rabadán (1991), aos de equivalência e inequivalência. Segundo a autora, a polissemia é uma das limitações linguísticas à expressão de equivalência translêmica que deriva das dificuldades impostas pelo uso motivado dos signos linguísticos no texto. Ela a define como uma condensação de significados em um único significante e cita Dagut (1981 apud RABADÁN, 1991, p. 120), que atribui essa condensação de significados "à capacidade limitada dos humanos para armazenar informação". Rabadán (1991, p. 119) observa ainda que a "natureza polissêmica" das línguas pode ser "explorada de forma consciente", constituindo o que denomina ambiguidade intencional, que representa "uma das barreiras mais difíceis de derrubar (se é que é possível fazê-lo) na transferência de um texto fonte ao polissistema meta [que constituem] os casos de inequivalência linguística (CATFORD apud RABADÁN, 1991, p. 120)". Tal inequivalência apresenta diferentes graus de dificuldade, que afetam a equivalência potencial. Aqueles casos em que a unidade léxica potencialmente polissêmica é utilizada de forma neutra com um significado determinado pelo contexto representam um nível de dificuldade menor do que os casos em que a unidade polissêmica é utilizada de forma intencional pelo autor, desempenhando um papel importante na organização do texto, como acontece com os jogos de linguagem de Romeu e Julieta.

Dentre os exemplos dessa ambiguidade resultante da exploração intencional da polis-

13 Esta tradução e todas que seguem de Rabadán (1991) são de nossa autoria.

14 No original: Cuanto mayor sea la relevancia de la función intratextual, mayor será el grado de dificultad en la transferencia y por lo tanto la actualización de la equivalencia potencial se verá reducida hasta los umbrales mismos de la traducción. En la mayoría de los casos es posible una traducción semântica, pero si los significantes se han constituido en significado, en contenido, y su materialidad formal no es transferible, es imposible la expresión de la equivalencia en el TM. 
semia citados por Rabadán, encontra-se o jogo de linguagem do soneto 135 de Shakespeare, que utiliza a palavra will com quatro sentidos distintos: o do substantivo vontade ou desejo sexual, o do substantivo órgão sexual mascuino, o do verbo auxiliar defectivo de futuro, e o diminutivo do nome William. A impossível reprodução simultânea dos jogos de linguagem, que não encontram um único equivalente no português para os quatro significados distintos de will, representa uma fonte de inequivalência. A partir da comparação do soneto original e sua respectiva tradução ao espanhol, Rabadán (1991, p. 122) conclui que

Os três valores linguísticos que a palavra Will tem no original ("desejo", "órgãos sexuais" e o nome do poeta) são o esqueleto sobre o qual está constituído o poema. Em espanhol é impossível pensar em uma unidade léxica que acumule os três sentidos e permita manter o jogo de equívocos, portanto há que se tomar partido e escolher a acepção em cada uma das aparições do termo. A versão de C. PÉREZ ROMERO (1987) evidencia a limitação: a palavra Will se mantém entre aspas (tradução zero) em três ocasiões no texto castelhano, presumivelmente naquelas em que a tradutora os interpretou como uma referência ao nome do autor. Nos demais casos se alternam "desejo" e "querer", ao passo que a referência sexual desapareceu por completo. (RABADÁN, 1991, p. 122)

Exemplo semelhante na obra que analisamos se encontra em uma fala de Mercúcio (ato I, cena 4): "And to sink in it should you burden Love" (Evans apud Funck, 2011, p. 60). O jovem, em uma tentativa de animar Romeu, que sofre por um amor não correspondido antes de haver se apaixonado por Julieta, explora o duplo sentido das expressões sink e burden, que significam, respectivamente, "afundar ou penetrar sexualmente" e "peso" ou "fazer peso sobre a mulher durante a cópula” (EVANS, 1997, apud FUNCK, 2011, p. 60).

Outra possibilidade de exploração da polissemia ou ambiguidade intencional referida pela autora diz respeito aos jogos de palavras. Rabadán observa que esses jogos representam a ruptura da relação que comumente se dá entre significante e significado e que isso se dá através da homonímia, da homofonia e da paronímia.

A homonímia ocorre quando um significante presta suporte a vários significados de forma motivada em um texto produzindo uma ambiguidade intencional: em Romeu e Julieta, a expressão to raise a spirit in his mistress 'circle, acima mencionada, utilizada por Mercúcio em referência à consumação do ato sexual entre Romeu e sua amada ilustra esse uso.

A homofonia consiste na existência de um único significante com significados divergentes, mas de mesma pronúncia. Novamente em Romeu e Julieta (cena 1), vê-se uma ilustração desse fenômeno: quando Mercúcio novamente faz referência ao amor, Shakespeare joga com a pronúncia idêntica de tale (conto, história) e tail (rabo), que resulta em um novo jogo de linguagem de conotação sexual de difícil reprodução em português, pois os substantivos em questão não são homófonos:

\section{Mercutio: Thou desirest me to stop in my tale against the hair. ${ }^{15}$ Mercúcio: Tu queres que eu pare minha história contra minha vontade? ${ }^{16}$}

A paronímia, por sua vez, consiste nos signos com significado distinto, mas com significantes relativamente próximos. Na cena 1 do ato I, dois servidores dos Capuleto, numa referência à superioridade de seus senhores sobre os rivais, os Montéquio, fazem uso de

15 Evans apud Funck, 2011, p. 113.

16 Funck, 2011, p. 113. 
jogos de linguagem de conotação sexual. A paronímia se encontra precisamente no uso das expressões heads of the maids (cabeças das donzelas) e maindenheads (cabaços):

Gregory: The quarrel is between our masters, and us their men.

Sampson: 'Tis all one, I will show myself a tyrant: when I have fought with the men, I will be civil with the maids; I will cut off their heads.

Gregory: The heads of the maids?

Sampson: Ay, the heads of the maids, or their maidenheads, take it in what sense thou wilt. $^{17}$

Gregório: A briga é entre nossos patrões e entre nós, seus criados.

Sansão: Dá na mesma; vou ser tirano: depois de lutar com os homens, vou ser bonzinho com as donzelas: cortarei suas cabeças.

Gregório: As cabeças das donzelas?

Sansão: Sim, suas cabeças ou seus cabaços, entende como quiseres. ${ }^{18}$

Finalmente, ainda no que se refere às possíveis formas de exploração intencional da polissemia relacionadas aos jogos de linguagem, Rabadán (1991) menciona a oligossemia e a metáfora.

A oligossemia compreende as diferenças não apenas linguísticas como também culturais existentes entre pares de línguas diversos. Elementos referentes a aspectos culturais específicos, tais como costumes muito particulares de determinada cultura, referências a fatos históricos, políticos ou mesmo a nomes próprios representam muitas vezes uma tarefa árdua para o tradutor e, de acordo com a autora, em alguns casos são fonte de inequivalência. No que se refere à obra aqui analisada, as referências a elementos da cultura e da história da Inglaterra elisabetana constituem exemplos de oligossemia. A expressão we'll not carry coals (ato I, cena 1), que significa literalmente "não carregaremos carvão", conota inferioridade: é empregada por Sansão, em seu diálogo inicial com Gregório, no qual ambos falam acerca da superioridade de seus amos, os Capuleto, sobre os inimigos Montéquio. A compreensão do real efeito do emprego dessa expressão, no entanto, requer do público um conhecimento extralingüístico: to carry coals era sinônimo de "rebaixar-se" em alusão a uma das profissões mais aviltadas da Idade Média, a dos carregadores de carvão. Nesse caso a solução tradutória pode se dar através de uma nota de rodapé, à qual recorre Funck (2011), ou através da busca de expressões equivalentes na língua-alvo que indiquem inferioridade, tais como "não podemos levar desaforo pra casa" (VIEGAS-FARIAS, 1998, p. 13), "desaforo não se engole" (HELIODORA, 2004, p. 21), ou "não vamos aguentar desaforos" (FUNCK, 2011, p. 22).

Quanto à metáfora, a autora observa que, apesar dos estudos desenvolvidos acerca dessa figura de linguagem, ela representa, ainda hoje, um desafio à tradução literária e que "o estudo da equivalência potencial da metáfora ainda está por ser feito" (RABADÁN, 1991, p. 135). Ela justifica sua afirmação "pela falta de uma definição clara, que permita incorporar o fenômeno à casuística geral no marco abstrato de uma teoria de transferência" (RABADÁN, 1991, p. 135), mas a define como "a aplicação, a um objeto ou fenômeno, do nome de outro, em virtude de uma relação de semelhança entre ambos” (RABADÁN, 1991, p. 135-136).

17 Evans apud Funck, 2011, p. 24.

18 Funck, 2011, p. 24. 
A partir da observação do comportamento das metáforas na tradução, Rabadán (1991, p. 135) propõe uma "classificação de graus de equivalência potencial da metáfora", subdividindo-as em tradicional, lexicalizada e inovadora, com base na sua função comunicativa.

As metáforas tradicionais são definidas como aquelas "institucionalizadas incorporadas pelo uso à tradição literária do polissistema e [que] têm por ele fortes conotações culturais" (RABADÁN, 1991, p. 140). Ou seja, o contato entre línguas e culturas diversas permite que determinadas metáforas sejam conhecidas por públicos diversos. No que se refere a Romeu e Julieta, a metáfora referente à penitência realizada no período da Quaresma (cena 4, ato II) é compartilhada por diferentes culturas do mundo cristão. Mercúcio provoca a Ama de Julieta, de idade avançada e, segundo ele, de aspecto pouco atraente, com uma metáfora obscena ao compará-la a uma "torta de quaresma que fica rançosa e mofada antes de ser comida" (FUNCK, 2011, p. 116), em decorrência do jejum no período que precedia a Páscoa, ou seja, a Quaresma.

As metáforas lexicalizadas são definidas como "aquelas que os falantes deixaram de perceber como tais e que passaram a formar parte do sistema linguístico e cultural e que, portanto, são utilizadas dentro dos limites de 'normalidade' que impõem as regras do polissistema” (RABADÁN, 1991, p. 142). Não identificamos exemplos desse tipo de metáforas nas falas selecionadas de Mercúcio na obra Romeu e Julieta. Acreditamos, porém, que a distância linguística, cultural e temporal que caracteriza tal texto requer um estudo mais aprofundado, que forneça recursos linguísticos, etimológicos ou mesmo históricos para sua identificação.

Já as metáforas inovadoras "representam o grau máximo de violação das regras linguísticas e literárias do polissistema sincrônico" (RABADÁN, 1991, p. 136), uma vez que se baseiam em referências culturais da cultura da língua-fonte desconhecidas pela cultura da língua-alvo. Sua presença em um texto representa uma grande dificuldade para a reprodução da função comunicativa da metáfora na língua-alvo, se esta carece das mesmas referências culturais, literárias, históricas que permitam buscar uma identificação com a cultura do texto fonte. Acreditamos que as metáforas que fazem parte dos jogos de linguagem da obra analisada Romeu e Julieta, ou pelo menos sua maioria, podem ser classificadas como metáforas inovadoras, por serem parte integrante de um texto de aproximadamente quatrocentos anos, caracterizado não só pela distância linguística como também cultural e temporal. Como exemplo, a metáfora "carne peixificada" empregada por Mercúcio (ato II, cena 4) em referência à falta de libido, já que, na era elisabetana, atribuía-se a falta de libido ao consumo da carne de peixe (FUNCK, 2011, p. 110):

\section{Mercutio: O flesh, flesh, how art thou fishified! ${ }^{19}$ \\ Mercúcio: Ó, carne, carne, como estás peixificada! ${ }^{20}$}

Além disso, a tradução de metáforas entre línguas heteromórficas como o inglês e o português, por exemplo, também dificulta a reprodução da função comunicativa, solucionada, em muitos casos, por meio de uma tradução semântica. Em Romeu e Julieta, as expressões as pop'ring pear, medlars e open arse, empregadas por Mercúcio (ato II, cena 1), são um exemplo dessa falta de correspondência (ou inequivalência) de referências linguísticas e culturais entre a cultura do texto fonte e a do texto alvo. A conotação obscena dessas expressões na era elisabetana, facilmente reconhecida pelo público daquela época como uma referência aos nomes vulgares do órgão sexual masculino e do feminino, respec-

19 Evans apud Funck, p. 10, 2011.

20 Funck, 2011, p. 110. 
tivamente, não se mantém na língua e cultura brasileiras. As soluções elencadas nesta pesquisa ou recorreram a notas de rodapé que explicam essa diferença linguística e cultural ou buscam recursos diversos do original, como o emprego de adjetivos que tentem reproduzir a conotação obscena das metáforas. Dessa forma, vemos medlars traduzido como "pêssego" (VIEGAS-FARIAS, 1998), “ameixa” (HELIODORA, 2004) ou "nêspera" (FUNCK, 2011), que, evidentemente, não reproduzem a insinuação obscena da metáfora original. No entanto, essa conotação é recuperada pelo emprego de substantivos diversos ou de adjetivos como "um par de nádegas que se entrega" e "pêra rija" (VIÉGAS-FARIAS, 1998), ou "se ela fosse uma etc. aberta" ou "pêra pontuda" (FUNCK, 2011; HELIODORA, 2004).

Faz-se necessário, por conseguinte, um estudo minucioso dessas expressões polissêmicas, uma compreensão que vá além do simples conhecimento da língua e que também se estenda ao âmbito do conhecimento histórico e cultural, dos hábitos, dos valores e do uso da linguagem e seu efeito na era elisabetana. Um estudo que nos leve a compreender o poder que esses jogos de palavras exerciam sobre a plateia de Shakespeare e o fascínio que ela sentia em tentar desvendá-los.

\section{Metodologia}

Para proceder ao levantamento e à análise das ocorrências de polissemia na obra Romeu e Julieta, nas passagens de falas de Mercúcio, e à comparação das diferentes soluções encontradas pelos tradutores Viégas-Farias (1998), Heliodora (2044) e Funck (2011), a pesquisa se distribuiu em cinco etapas:

1) Escolha da tradução interlinear de Funck como fonte do texto original em inglês para a coleta dos jogos de linguagem e sua tradução para o português (2011). Essa tradução tem cunho didático, uma vez que está voltada a estudantes e profissionais das áreas de literatura e tradução. Sua linguagem, mais próxima da original, é complementada por notas de rodapé, especialmente nos casos em que os jogos de linguagem e as metáforas são construídos a partir de referências a expressões arcaicas do inglês ou mesmo a fatos históricos e culturais considerados relevantes. É produzida em prosa, ao contrário do texto original, escrito "predominantemente em poesia, em pentâmetros pela versificação inglesa, nem sempre rimados" (FUNCK, 2011, p. 17).

2) Escolha das traduções de Viégas-Faria (1998) e Heliodora (2004), mais próximas da linguagem coloquial e da cultura contemporâneas. Elas não recorrem a notas de rodapé, mas isso não as impede de recriar os jogos de linguagem do texto fonte através de recursos variados. Por outro lado, embora se trate de traduções com mesmo público e objetivo, observamos uma sutil diferença no que diz respeito ao nível de coloquialismo e à forma das traduções: Viégas-Farias emprega uma linguagem mais coloquial, e sua tradução, escrita em prosa, parece soar mais contemporânea, estando voltada a um público mais habituado a ler prosa do que verso. Essa sutileza ora aproxima, ora distancia as duas traduções.

3) Identificação dos jogos de linguagem no original e de suas traduções em todas as falas de Mercúcio, personagem que impulsiona os acontecimentos da peça por meio de sua linguagem sarcástica impregnada de jogos de linguagem de conotação obscena. Os dados que consistem nas falas de Mercúcio foram organizados em tabelas de acordo com o ato e a cena da peça. As tabelas contêm o texto original, seguidas das respectivas traduções.

4) Comparação do original e das traduções para identificar as soluções dadas e análise das estratégias de tradução dos jogos de linguagem empregadas por cada tradutor, com uma atenção especial aos casos de inequivalência. A análise está baseada em glossários es- 
pecializados, que permitiram uma melhor interpretação e percepção desses jogos de linguagem: Eric Partridge (1968), Frankie Rubenstein (1989), Michael Macrone (1998) e Pauline Kiernan (2014), além da tradução interlinear de Romeu e Julieta de Elvio Funck (2011).

5) Comparação das três traduções entre si. A análise das distintas traduções dos jogos de linguagem e sua comparação permitiu que identificássemos as também distintas estratégias e/ou recursos empregados no processo tradutório, fossem eles o emprego de expressões equivalentes dos jogos de linguagem no próprio texto ou notas de rodapé que esclarecessem aspectos linguísticos, culturais e históricos que tornassem determinadas expressões jogos de linguagem.

\section{Análise dos jogos de linguagem}

Na obra Romeu e Julieta, a utilização de linguagem obscena e os padrões de decência são perceptíveis especialmente através das falas do personagem Mercúcio. A Mercúcio, de família rica e nobre, está reservada uma linguagem mais elaborada e os jogos de linguagem cômicos mais espirituosos, conforme se verá na análise a seguir. Vale ressaltar que esses jogos representam um grande desafio aos tradutores, que se deparam com expressões cuja conotação sexual evidente na era elisabetana se perdeu com o decorrer do tempo.

Das expressões analisadas que compõem os jogos de linguagem da obra Romeu e Julieta, poucas mantêm atualmente a conotação sexual, tais como prick e cock, que designam de forma vulgar o órgão sexual masculino, conforme os registros de dicionários da língua inglesa contemporânea. Daí a necessidade de consultar dicionários ou glossários especializados para uma melhor interpretação e percepção dos jogos de linguagem.

A seguir serão analisadas as falas de Mercúcio destacadas em alguns atos e cenas de Romeu e Julieta.

\begin{tabular}{|c|c|c|c|}
\hline $\mid \begin{array}{c}\text { ATO II } \\
\text { Cena 1 - original - Evans } \\
\text { (apud Funck) }\end{array}$ & Funck & Viégas-Faria & Heliodora \\
\hline $\begin{array}{l}\text { Mercutio: This cannot } \\
\text { anger him; 'twould an- } \\
\text { ger him to raise a spirit } \\
\text { in his mistress' circle, of } \\
\text { some strange nature, let- } \\
\text { ting it there stand till she } \\
\text { had laid it and conjured } \\
\text { it down: that were some } \\
\text { spite. My invocation is fair } \\
\text { and honest: in his mistress } \\
\text { name I conjure only but to } \\
\text { raise up him. (p. } 83-84)\end{array}$ & $\begin{array}{l}\text { Mercúcio: Não é isso } \\
\text { que vai irritá-lo e sim er- } \\
\text { guer um espírito dentro } \\
\text { do círculo de sua amada, } \\
\text { de natureza um tanto } \\
\text { estranha, e deixá-lo ali } \\
\text { ereto até que ela o faça } \\
\text { deitar e o esconjure a se } \\
\text { abaixar: isso sim é que se- } \\
\text { ria despeito. Minha escon- } \\
\text { juração é justa e honesta: } \\
\text { em nome de sua amada, eu } \\
\text { apenas o esconjuro a rea- } \\
\text { parecer. (p. 83-84) }\end{array}$ & $\begin{array}{l}\text { Mercúcio: Isso não o } \\
\text { aborrecerá. O que pode } \\
\text { deixá-lo aborrecido é in- } \\
\text { vocar um espírito de } \\
\text { natureza estranha para } \\
\text { dentro do círculo de sua } \\
\text { amada e deixá-lo ali ficar, } \\
\text { até que ela o deitasse por } \\
\text { terra, até ela esconjurá- } \\
\text {-lo; isso sim, seria mes- } \\
\text { quinho. Minha invoca- } \\
\text { ção é bem intencionada, } \\
\text { honesta, e, pelo nome de } \\
\text { sua amada, conjuro-o tão } \\
\text { somente para chamá-lo à } \\
\text { vida. (p. 48) }\end{array}$ & $\begin{array}{l}\text { Mercúcio: Não sei por } \\
\text { quê. Poderia zangar-se se } \\
\text { eu invocasse algum po- } \\
\text { tente espírito pra pene- } \\
\text { trar o círculo da amante, } \\
\text { que fosse estranho e ali } \\
\text { ficasse, ereto, até que ela } \\
\text { chegasse a derrubá-lo: } \\
\text { Lá isso era maldade. A mi- } \\
\text { nha reza é clara e limpa! } \\
\text { Em nome de quem ama só } \\
\text { peço que ele cresça e apa- } \\
\text { reça. (p. 62) }\end{array}$ \\
\hline
\end{tabular}

No início da cena 1 do ato II, Mercúcio faz provocações a Romeu ao referir-se ao desejo sexual de seu amigo por Rosalina, por quem Romeu estivera apaixonado antes de conhecer Julieta no baile dos Capuleto. No original, observam-se insinuações de cunho 
malicioso especialmente nas expressões "raise a spirit in his mistress' circle”, já mencionada, e "letting it there stand till she had laid it and conjured it down".

Segundo Funck (2011, p. 83)

\begin{abstract}
'Esconjurar' também significava usar de passes de magia para ressuscitar um morto. Em inglês, raise a spirit significava literalmente, 'levantar um espírito', 'fazer aparecer um espírito', mas como a palavra spirit também significava 'pênis', Mercúcio está se aproveitando desse duplo sentido para se referir à ereção". Cf. Gibson e outros intérpretes: a palavra circle conota 'vagina', sentido que se coaduna com o linguajar atrevido de Mercúcio, neste contexto (GIBSON, p. 50). Este circle, como explica Mercúcio, é de 'estranha' natureza, ou seja, nada tem a ver com a geometria. Para o duplo sentido de spirit, cf. Rubesntein, $\mathrm{p}$. 250. As palavras circle e nothing, bem como o O (maiúsculo), eram frequentemente usadas como eufemismos e se referiam à genitália feminina.
\end{abstract}

Funck (2011, p. 83) ainda observa que a fala de duplo sentido de Mercúcio significa que "seria altamente ofensivo se alguém procurasse seduzir Rosalina, pois seria um ato de traição para com Romeu". Acrescenta que, através da fala de Mercúcio I conjure only but to raise up him, Rubenstein (p. 54) "explica o duplo sentido de conjure" como o de "congresso carnal" (p. 84). Rubenstein (1989, p. 213) também observa as conotações sexuais de raise entendido como uma "ereção"; assim como de spirit, "pênis" (RUBENSTEIN, 1989, p. 250).

A tradução de Funck mantém a conotação sexual por meio das expressões "erguer um espírito dentro do círculo de sua amada", "deixá-lo ali ereto até que ela o faça deitar e o esconjure a se abaixar" e "eu apenas o esconjuro a reaparecer", que fazem referência não apenas à ereção, mas também à penetração e à ejaculação, ao clímax do ato sexual. Viégas-Faria mantém o jogo de linguagem de conotação obscena quando faz referência ao ato sexual (ereção, penetração, clímax/orgasmo): "invocar um espírito dentro do círculo [...] para dentro do círculo de sua amada e deixá-lo ali ficar, até que ela o deitasse por terra...". Da mesma forma, Heliodora assegura a conotação sexual em sua tradução em referência à ereção, à penetração e ao clímax quando escreve: “... invocasse algum potente espírito pra penetrar o círculo da amante, que fosse estranho e ali ficasse ereto, até que ela chegasse a derrubá-lo:...". Consideramos que as expressões "conjuro-o tão somente para chamá-lo à vida" e "peço que ele cresça e apareça", de Viégas-Farias e Heliodora respectivamente, têm a mesma conotação sexual evidente do original I conjure only but to raise up him, pois aludem à ereção.

\begin{tabular}{|c|c|c|c|}
\hline $\begin{array}{c}\text { ATO II } \\
\text { Cena } 1 \text { - original- Evans } \\
\text { (apud Funck) }\end{array}$ & Funck & Viégas-Faria & Heliodora \\
\hline $\begin{array}{l}\text { Mercutio: If love is blind, } \\
\text { love cannot hit the mark. } \\
\text { Now will he sit under a } \\
\text { medlar tree, and wishis } \\
\text { mistress were that kind of } \\
\text { fruit as maids call medlars } \\
\text { when they laugh alone. }\end{array}$ & $\begin{array}{l}\text { Mercúcio: Se o amor é } \\
\text { cego, não vai conseguir } \\
\text { acertar o alvo. Agora ele } \\
\text { vai sentar debaixo de uma } \\
\text { nespereira e ficar dese- } \\
\text { jando que sua amada seja } \\
\text { aquele tipo de fruta que } \\
\text { as donzelas chamam de } \\
\text { nêspera quando riem so- } \\
\text { zinhas. }\end{array}$ & $\begin{array}{l}\text { Mercúcio: Se o amor é } \\
\text { cego, não pode acertar } \\
\text { o alvo. Agora ele vai se } \\
\text { sentar sob um pessegueiro } \\
\text { e desejar que sua amada } \\
\text { fosse aquele tipo de fruto } \\
\text { que as donzelas chamam } \\
\text { de pêssego quando riem } \\
\text { sozinhas. }\end{array}$ & $\begin{array}{l}\text { Mercúcio: Amor que é } \\
\text { cego não acerta o alvo; } \\
\text { ele vai se encostar numa } \\
\text { ameixeira, querer que a } \\
\text { amada fosse fruta igual } \\
\text { à que faz rirem, em se- } \\
\text { gredo, as moças, e quase } \\
\text { sempre elas chamam de } \\
\text { ameixa. }\end{array}$ \\
\hline
\end{tabular}


\begin{tabular}{l|c|c|c|c|}
\hline O Romeo, that se were, & Ó Romeu, quem dera & Oh, Romeu, se ela fosse, & Ai, Romeu, aí! Se ao me-
\end{tabular} $O$ that she were an open- ela fosse, ó, quem dera oh, se ela fosse um par de nos ela fosse uma ameiarse, thou a pop'ring ela fosse uma etc. aberta nádegas que se entrega, xa, e você pêra pontuda! pear! Romeo, good night, e tu uma pera pontuda! e tu, uma pêra rija! - Ro- Canteiro é muito frio pra I'll to my truckle-bed. This Romeu boa noite, vou para meu, boa noite. Recolho- ser cama. Vamos embora? field-bed is too cold for me a cama. Esta cama ao ar -me à minha cama, que (p. 62-63)

to sleep. Come, shall we livre é fria demais para eu este leito a céu aberto é go? (p. 84-85) ra? (p. 84-85)

sono. Então, vamos indo? (p. 48-49)

Nesse trecho, ainda na cena 1 do ato II, Mercúcio segue com suas provocações. No original, os jogos de linguagem de conotação sexual se encontram na expressão hit the mark, medlar, pop'ring pear laugh e open arse. Hit the mark é um termo da artilharia traduzido como "acertar o alvo". Na era elisabetana, também conotava "manter relações sexuais" (GIBSON apud FUNCK, 2011, p. 84). Portanto, Mercúcio sugere que Romeu "acertaria seu alvo", ao relacionar-se sexualmente com a amada.

As frutas medlar (pêssego), e pop'ring pear (pêra), naquela época, eram popularmente utilizadas para se referir, respectivamente, aos órgãos sexuais feminino e masculino, devido a seu formato sugestivo. Daí a conotação obscena dessa metáfora das frutas. No entanto, no contexto atual essas frutas não têm a mesma conotação sexual da época de Shakespeare, especialmente para um público leitor de língua, cultura e época diversas. Portanto, os recursos utilizados pelos tradutores a fim de manter a conotação obscena do original são, da mesma forma, diversos, adaptados a seu público contemporâneo. Laugh (rir ou riso), na época, era uma palavra de conotação sexual e, portanto, usada como um trocadilho que sugeria uma referência a relações sexuais. Nesse contexto, when they laugh alone faz alusão a conversas de cunho sexual entre as moças na intimidade. Open arse também tinha conotação obscena na época, além de ser uma gíria, um nome vulgar para as nádegas que, aliado ao uso do adjetivo open (abertas), enfatiza a obscenidade.

Nas traduções de Funck e Viégas-Faria, respectivamente, vemos a conotação sexual através das expressões "ficar desejando que sua amada seja aquele tipo de fruta que as donzelas chamam de nêspera quando riem sozinhas" e "...desejar que sua amada fosse aquele tipo de fruto que as donzelas chamam de pêssego quando riem sozinhas", em referência ao riso provocado por conversas íntimas de cunho sexual; ou ainda, em "quem dera ela fosse uma etc. aberta e tu uma pera pontuda" e "se ela fosse um par de nádegas que se entrega e tu, uma pêra rija!", em referência ao ato sexual, à penetração. As mesmas referências ao ato sexual são observadas na tradução de Heliodora, em "querer que a amada fosse fruta igual à que faz rirem, em segredo, as moças, e quase sempre elas chamam de ameixa" e "Se ao menos ela fosse uma ameixa, e você pêra pontuda!".

No entanto, acreditamos que, ao contrário do texto original, a conotação sexual das frutas referidas não se manteve nas três traduções analisadas, uma vez que no contexto de um leitor contemporâneo brasileiro essas frutas não são associadas ao prazer sexual. Portanto, o que evidencia a obscenidade são as expressões "riem sozinhas", em alusão a conversas íntimas e de cunho sexual entre as moças, ou a expressão "pêra pontuda", que, devido a seu formato, alude ao órgão sexual masculino. Talvez a utilização de outras frutas adaptadas à cultura de chegada tornasse a conotação obscena mais evidente a um público (como banana, por exemplo, para se referir ao homem) contemporâneo e geral. 


\begin{tabular}{|c|c|c|c|}
\hline $\begin{array}{c}\text { ATO II } \\
\text { Cena } 4 \text { - original - } \\
\text { Evans (apud Funck) }\end{array}$ & Funck & Viégas-Faria & Heliodora \\
\hline \begin{tabular}{|} 
Ama: God ye good mor- \\
row, gentlemen. \\
Mercutio: God ye good \\
den, fair gentlewoman. \\
Nurse: Is it good den? \\
Mercutio: 'Tis no less, I \\
tell ye, for the bawdy hand \\
of the dial is now upon the \\
prick of noon. \\
Nurse: Out upon you! \\
What a man are you? (p. \\
$114-115$ )
\end{tabular} & $\begin{array}{l}\text { Ama: Que Deus lhes dê } \\
\text { uma boa manhã, cavalheiros. } \\
\text { Mercúcio: Que Deus lhes } \\
\text { dê boa tarde, bela senhora. } \\
\text { Ama: Já é tarde? } \\
\text { Mercúcio: Nada menos, } \\
\text { pois, no mostrador, o pon- } \\
\text { teiro safado está agora } \\
\text { bem em cima do ponto } \\
\text { do meio-dia. } \\
\text { Ama: Arreda-te daqui! } \\
\text { Que diabo de homem és } \\
\text { tu? (p. 114-115) }\end{array}$ & $\begin{array}{l}\text { Ama: Deus vos dê bom } \\
\text { dia, cavalheiros. } \\
\text { Mercúcio: Deus lhes dê } \\
\text { boa tarde, gentil senhora. } \\
\text { Ama: Já é boa tarde? } \\
\text { Mercúcio: Nada menos } \\
\text { que tarde, lhe asseguro; } \\
\text { pois a mão obscena que é } \\
\text { a sombra do ponteiro do } \\
\text { relógio de sol encontra- } \\
\text {-se agora sobre o pau que } \\
\text { traça o meio-dia. } \\
\text { Ama: Passa fora! Que } \\
\text { tipo de homem és tu? (p. } \\
68 \text { ) }\end{array}$ & $\begin{array}{l}\text { Ama: Deus lhes dê } \\
\text { bons-dias, cavalheiros! } \\
\text { Mercúcio: Que Deus lhes } \\
\text { dê boa noite, bela dama. } \\
\text { Ama: É boa-noite? } \\
\text { Mercúcio: Nada menos } \\
\text { do que isso, pois o safado } \\
\text { do ponteiro do sol está } \\
\text { nesse momento cobrindo } \\
\text { a marca do meio-dia. } \\
\text { Ama: Ora, pare com } \\
\text { isso. Que tipo de homem } \\
\text { é esse? (p. } 83 \text { ) }\end{array}$ \\
\hline
\end{tabular}

Na cena 4 do ato II, Mercúcio dirige suas provocações à Ama de Julieta, que o encontra em uma praça quando está à procura de Romeu, a quem deve dar um recado de sua amada Julieta. No original, existe um duplo sentido de conotação evidente através do uso da expressão den (toca, refúgio), que, segundo Funck (2011, p. 114), "também conotava 'antro' e 'vagina' (PARTRIDGE, 2009, p. 117)", assim como da expressão for the bawdy hand of the dial is now upon the prick of noon, em que prick conota "ponto", "marca", mas também "pênis" e hand, "mão" ou "ponteiro do relógio". Também bawdy, conforme Macrone (1998, p. 182) conota algo obsceno, lascivo.

Funck (2011, p. 115) acrescenta em noda de rodapé que

O duplo sentido da frase de Mercúcio, que merece a indignação da Ama, é difícil de traduzir, mas basta lembrar que prick, além de "ponto", "marca", conota "pênis". Em inglês, hand, "mão", também significa "ponteiro do relógio". Mercúcio reforça seu sentido malicioso com um gesto indecente e com seu tom de voz provocante. Evans afirma que dial, por seu formato em O, conotava "vagina" (p. 124). Cf. a tradução livre de Nuno: “... o ponteiro do relógio está durinho como um pau apontado para cima”. (p. 65)

No que tange a den em good den (boa noite), proveniente de good even, forma contracta de good evening (boa noite), concluímos que a conotação sexual de den (antro, vagina) se perde no português e, consequentemente, nas traduções analisadas. Funck e Viégas-Faria traduzem den como "boa tarde" e Heliodora como "boa noite".

A respeito da expressão for the bawdy hand of the dial is now upon the prick of noon, observamos que as três traduções mantiveram o jogo de linguagem do original sugerindo a obscenidade de Mercúcio, que faz referência ao ato sexual. Funck traduz como "o ponteiro safado está agora bem em cima do ponto do meio-dia"; Viégas-Faria traduz como "a mão obscena... encontra-se agora sobre o pau que traça meio-dia"; Heliodora como "o safado do ponteiro do sol está nesse momento cobrindo a marca do meio-dia".

É importante observar que a interpretação da Ama de Julieta em relação a essa fala de Mercúcio é essencial para que o jovem alcance seu objetivo de provocá-la através de uma nova obscenidade. A reação da Ama, mostrando-se ultrajada, complementa o efeito cômico almejado pelo autor da peça. Em sua dissertação de mestrado, Viégas-Faria (1999) analisa essas falas e se utiliza da Teoria das Implicaturas de Paul Grice, pela qual essa 
obscenidade só ficaria clara através da correta interpretação da Ama em relação à fala de Mercúcio; o que de fato acontece quando a mesma lhe responde "Passa fora! Mas que tipo de homem és tu?".

\section{Considerações finais}

A análise e comparação das traduções de Romeu e Julieta de Funck (2011), Viégas-Faria (1998) e Heliodora (2004) permitiu corroborar a hipótese de que o efeito cômico provocado pelos jogos de linguagem do texto original de Romeu e Julieta requeria recursos linguísticos diversos dos originais naqueles casos em que os mesmos não pudessem ser reproduzidos na língua de chegada, conservando todos os significados de cada significante motivado empregado por Shakespeare: a maioria dos jogos de linguagem de Mercúcio representava uma fonte de inequivalência, e os tradutores necessitaram buscar estratégias de compensação para recriar jogos de linguagem que mantivessem tanto a função comunicativa de comicidade quanto a linguagem característica dos personagens.

No que se refere às traduções analisadas de Romeu e Julieta, concluímos que o objetivo ou escopo da tradução, nesse caso o de manter a função comunicativa dos jogos de linguagem do texto original, bem como o público-alvo (público leitor e não espectador do teatro) foram fatores determinantes para as estratégias e escolhas tradutórias diversas, porém igualmente eficientes, dos três tradutores em questão.

A tradução de Funck, que tem um cunho didático, uma vez que está voltada a um público constituído por estudantes de literatura e de tradução, professores, pesquisadores e tradutores, reproduziu os jogos de linguagem obscenos, ora por meio de notas de rodapé com informações relevantes acerca de questões linguísticas, etimológicas, históricas e culturais necessárias para a compreensão e análise desses jogos, ora por meio da recriação dos jogos de linguagem no próprio texto.

As traduções de Viégas-Faria e Heliodora, voltadas ao público geral, que busca primordialmente entretenimento, também reproduziram a função comunicativa dos jogos de linguagem do texto original através do emprego de recursos linguísticos do português brasileiro atual que possibilitaram sua identificação pelo público-alvo. Portanto, no que diz respeito a esse público, observamos uma proximidade entre ambas as traduções. No entanto, no que tange à linguagem e à finalidade, percebemos um distanciamento entre elas, uma vez que a tradução dos jogos de linguagem de Heliodora, cujo texto em prosa e verso marcado pela sonoridade se destina à representação teatral, emprega uma linguagem mais sutil que a de Viégas-Faria, cujo texto em prosa se destina à leitura. Ressaltamos que essas diferenças não comprometem o caráter cômico e sarcástico da linguagem do personagem Mercúcio, alvo de análise do presente trabalho.

Além disso, acreditamos que os três tradutores recorreram, com sucesso, a soluções alternativas ou diversas do texto original, como uma estratégia de compensação, naqueles casos de inequivalência, em que a língua de chegada carecia de recursos que possibilitassem uma reprodução muito próxima dos jogos de linguagem do texto original. Em outras palavras, as soluções alternativas encontradas pelos tradutores naqueles casos de inequivalência, que os levaram a explorar de forma motivada os duplos sentidos de significantes empregados por Shakespeare, recriando, assim, novos jogos de linguagem, não só não comprometeram a qualidade de suas traduções, uma vez que a característica da linguagem do texto original foi preservada dentro dos limites possíveis da tradução, como também acrescentaram contemporaneidade ao texto shakesperiano. 
Concluímos, dessa forma, que as duas estratégias de tradução apresentadas, a de Funck, mais próxima ao texto original tanto na forma como no conteúdo, caracterizada pelo uso frequente de notas de rodapé, e as de Viégas-Faria e Heliodora, mais adaptadas aos padrões linguístico-culturais do Brasil contemporâneo, são eficientes e capazes de reproduzir a função comunicativa do texto shakespeariano. Portanto, visualizamos dois caminhos distintos, porém igualmente eficientes, determinados pelo objetivo do tradutor e por seu público-alvo. Entretanto, acreditamos que aqueles casos que ultrapassam o limite linguístico por fazerem referências a fatos históricos e culturais da Inglaterra elisabetana, provavelmente desconhecidos do público contemporâneo em geral, representam os casos de inequivalência de maior desafio para o tradutor. E é possível que a forma mais eficiente de solucioná-los seja, de fato, através do emprego das notas de rodapé, que permitem oferecer com mais clareza e precisão informações relevantes para uma maior compreensão do texto original.

Nos casos de inequivalência, resultantes da exploração da natureza polissêmica da língua através de várias formas - homonímia, homofonia, paronímia, metáfora, ou mesmo oligossemia (RABADÁN, 1991) -, observamos que as soluções tradutórias não se limitaram apenas a buscar recursos no âmbito linguístico, mas também no âmbito cultural, especialmente nos casos de oligossemia, em que os jogos de linguagem foram elaborados a partir da exploração de referências a fatos histórico-culturais da era elisabetana e necessitaram ser domesticados ou adaptados a referências da cultura de chegada. Houve situações também em que o tradutor recorreu a notas de rodapé a fim de oferecer um esclarecimento acerca das referências linguísticas e histórico-culturais específicas da época. No que diz respeito à equivalência linguística, observou-se, ainda, que são poucos os casos em que um jogo de linguagem encontra, na língua de chegada, uma equivalência muito próxima do texto original. Um dos exemplos citados por Funck (2011) em sua tradução de Romeu e Julieta é a expressão maidenhead, cuja tradução em português, a palavra "cabaço", embora represente uma equivalência muito próxima do original, tem uma carga de conotação obscena muito mais intensa do que no original.

\section{Referências}

EVANS, Ifor. História da literatura inglesa. Trad. A. Nogueira Santos. $4^{\mathrm{a}}$ ed. Lisboa: Edicões 70, 1976.

FUNCK, Elvio. Traduzir Shakespeare. Diário Catarinense Florianópolis, n. 8171, 23 ago. 2008.

. Uma breve história da Inglaterra. Porto Alegre: Movimento, 2011.

HURTADO ALBIR, Amparo. Traducción y traductología: introducción a la traductología. Madrid: Cátedra, 2001.

KIERNAN, Pauline. Filthy Shakespeare: Shakespeare's Most Outrageous Sexual Puns. London: Quercus Edition Ltd., 2008.

MACRONE, Michael. Naughty Shakespeare. London: Ebury Press, 1998.

PARTRIDGE, Eric. Shakespeare's Bawdy. $3^{\mathrm{a}}$ ed. London: Routledge, 1968.

RABADÁN, Rosa Alvaréz. Problemática de la equivalencia translémica inglés-español. León: Universidad de León; Secretariado de Publicaciones, 1991.

RUBENSTEIN, Frankie. A Dictionary of Shakespeare's Sexual Puns and their Significance. $2^{\mathrm{a}}$ ed. London: Palgrave Macmillan, 1989. 


\section{Conexão Letras}

SHAKESPEARE, William. Romeu e Julieta. Trad. Bárbara Heliodora. Rio de Janeiro, Nova Aguilar, 2004.

Romeu e Julieta. Trad. Beatriz Viégas-Faria. Porto Alegre, L\&PM, 1998, p. 23 Romeu e Julieta. Trad. Elvio Funck. Porto Alegre: Movimento/Edunisc, 2011. WELLS, Stanley. Shakespeare, Sex and Love. New York: Oxford University Press, 2010.

Recebido em: 18/05/17 Aceito em: 29/05/17 